\title{
Redes de políticas públicas e a condução de sociedades complexas
}

\author{
Volker Schneider*
}

Na ciência política atual, dois conceitos têm atrás de si uma carreira impressionante: os conceitos de "rede" e "governança". Ambos surgiram durante os anos 1970, principalmente na sociologia, e se espalharam durante os anos 1980 e 1990 também para outras disciplinas das ciências sociais, como a ciência política e a ciência econômica. Ambos os conceitos colocam em questão as estruturas e os contextos das relações entre Estado e sociedade, embora ambos representem basicamente idéias muito antigas. Contudo, no discurso teórico dos anos 1980 e 1990 foram "enriquecidos" com novos significados e se constituíram em conceitos que se referem a uma transformação do Estado e a uma relação modificada entre Estado e sociedade. Ambos os conceitos pontuam que a solução de problemas políticos modernos e relevantes por meio de políticas públicas somente é possível com base em novas estruturas políticas.

Nesse contexto, o presente artigo tem o objetivo de conceber redes de políticas públicas como uma nova forma de governança política e aqui relati-

Professor da Universität Konstanz, Alemanha. volker.Schneider@uni-konstanz.de. Texto original alemão traduzido por Hermílio Santos.

\begin{tabular}{|l|l|l|l|l|l|}
\hline Civitas & Porto Alegre & v. 5 & n. 1 & jan.-jun. 2005 & p. 29-58 \\
\hline
\end{tabular}


vamente tanto à teoria do estado como também à teoria das políticas públicas - portanto à teoria material do Estado. Inicialmente, serão abordados nas próximas seções os problemas do arranjo da governança e das redes de políticas públicas do ponto de vista da teoria do Estado. Num passo seguinte serão esboçadas as condições centrais que conduziram ao surgimento desses novos conceitos. Ao final, serão mencionadas implicações que esta transformação traz para as modernas teorias do Estado e da democracia.

\section{Governança e teoria do Estado}

Provavelmente a maioria dos teóricos do Estado está de acordo em conceber o objeto de sua construção teórica como uma área institucional determinada, que constitui seja um subsistema funcional ou uma entidade independente da influência externa da sociedade, que produz importantes resultados de condução e coordenação para a sociedade. A tarefa da teoria do Estado seria então: (1) descrever analiticamente o tema em suas diferentes facetas e delimitá-lo conceitualmente, (2) esclarecer sua gênese, (3) suas funções e por último, (4) esclarecer as formas de operação ou de ação dessa entidade.

$\mathrm{Na}$ minha opinião, as muitas teorias que se colocam essa difícil tarefa podem ser distinguidas em duas dimensões: primeiro, se uma teoria do Estado se orienta mais pelo conflito ou mais pela integração (Tainter, 1988), ou, segundo, se ela se funda em uma análise macro ou micro (Coleman, 1990). Essas dimensões do desenvolvimento teórico estão representadas na figura abaixo (Figura 1). 
Figura 1

Desenvolvimento teórico entre nível micro e macro e entre conflito e integração

\begin{tabular}{|c|c|c|}
\hline & Conflito & Integração \\
\hline $\begin{array}{l}\text { Análise } \\
\text { macro }\end{array}$ & $\begin{array}{c}\text { Teoria } \\
\text { Pluralista } \\
(1950-60)\end{array}$ & $\begin{array}{c}\text { Teoria dos } \\
\text { Sistemas } \\
(1960-70)\end{array}$ \\
\hline $\begin{array}{l}\text { Análise } \\
\text { micro }\end{array}$ & $\begin{array}{c}\text { Teoria da Ação } \\
\text { (1980) }\end{array}$ & $\begin{array}{c}\text { Teoria da } \\
\text { Governança } \\
\text { (a partir } \\
\text { de 1990) }\end{array}$ \\
\hline
\end{tabular}

Se começarmos a classificação da moderna teoria do estado com o institucionalismo tradicional, este se estabeleceu exclusivamente sobre o nível macro-social com o foco na ordem legal. Ordem social foi explicada na maioria das vezes com macro-instituições, como constituições, por exemplo (Friedrich, 1950). O pluralismo foi uma reação contrária, orientada pelo conflito, que se recusava em ver nas constituições políticas uma força integradora independente. Ao invés disso, assinalava as relações de força e poder que operavam atrás das instituições (Bentley, 1967; Truman, 1971). Se o Estado ali era mais que uma arena específica de disputa de grupos, então ele aparecia no máximo como um sistema institucionalizado, no qual esses conflitos eram estabelecidos de forma civilizada, ou enquanto um instrumentário institucional, que um grupo empregava para a manutenção de seu poder. Isso faz lembrar a sentença de Ferdinand Lassalle de que as constituições são apenas relações de poder transpostas para o papel (citado em Uexküll, 1974).

A teoria dos sistemas dos anos 1960 e 1970 foi uma reação à falta de questionamento sobre a integração social por meio de instituições estatais, na 
qual o estrutural-funcionalismo de Talcott Parsons assume uma posição proeminente (Parsons, 1966). O problema é que nele a integração das sociedades se restringiu fortemente a fatores culturais gerais, o que conduziu a pesquisa em ciência política para a análise de macroestruturas normativas e simbólicas gerais. Os estudos comparativos de Gabriel Almond (Almond e Powell, 1966) foram aplicações influentes desta concepção. Finalmente, nesse contexto deve ser mencionada também a abordagem de David Easton (1967), que se aplica a abordagens cibernéticas, mas que, no entanto - semelhante ao funcionalismo de Almond - descreve a relação entre situações de problema social e resultados de regras políticas e resultados de condução política como um contexto de "caixa preta" (para uma crítica ver Bunge, 1996).

Desde o fim dos anos 1960 essa teoria estrutural-funcionalista dos sistemas foi crescentemente criticada. A perspectiva do conflito como nova problemática teórica foi conduzida novamente ao primeiro plano. A partir da perspectiva marxista, estruturas de conflito foram situadas como "contradições sistêmicas" da luta de classes. Nessa fase do redescobrimento do problema do conflito, contudo, ocorreu novamente uma modificação que conduziu cada vez mais o foco analítico do nível macro para o nível micro. Sobretudo nos anos 1980 um número crescente de cientistas sociais exigiu que processos e fenômenos sociais devessem ser explicados como resultantes da ação de indivíduos e atores coletivos, ou seja, explicados a partir do nível micro. Uma marca dessa mudança é seguramente a crítica de Jon Elster ao funcionalismo marxista (Elster, 1982).

Nessa época ocorre também a mudança da teoria da comunicação, na qual a questão da integração das sociedades é colocada em segundo plano, mesmo para teóricos dos sistemas. Com o foco sobre a auto-organização, a questão da integração tornou-se uma obviedade não mais problematizada. Há algum tempo a questão da integração foi novamente colocada em primeiro plano com o patrocínio do foco analítico do nível micro - especialmente com apoio de variantes do institucionalismo. Passou então a ser discutido como a ordem social poderia ser reproduzida e mantida a despeito de interesses divergentes e racionalidade limitada. Isso implicava um retorno à perspectiva teórica sistêmico-cibernética, na qual a questão da capacidade de autocondução das sociedades é respondida com a micro-análise de instituições sociais e seus efeitos integrativos. O conjunto desses mecanismos de condução é dis- 
cutido há algum tempo como "governança" (Grote e Gbikpi, 2002; Benz, 2004; Mayntz, 2004, Schneider, 2004b).

Uma idéia fundamental está presente aqui, a de que a questão da ordem deverá ser respondida por meio de uma análise diferenciada dos mecanismos institucionais de condução. Esse novo paradigma evidentemente não surgiu do nada. Aqui também pôde ser construído sobre distintos pensamentos teóricos basilares, que podemos retroceder até os filósofos morais escoceses (Mayr, 1971). Novo na abordagem da governança é a tentativa de fundamentar a perspectiva microanalítica para mecanismos institucionais de coordenação. Trata-se da utilização de abordagens teórico-institucionais para estruturas de interação individual. Por esta razão governança deve ser traduzida em alemão como "condução institucional" (Kenis e Schneider, 1996). A esta idéia está vinculada uma análise das instituições centrada em atores (Mayntz e Scharpf, 1995; Scharpf, 2000). Isso não significa, porém, que se deve partir necessariamente de uma teoria da ação racional. O objetivo é explicar a ausência de problemas de atores individuais e coletivos com referência a orientações específicas de ação e contextos institucionais de ação. Além disso, não é obrigatório que os atores decidam racionalmente. Modelos alternativos explicam a ação seja por meio de comportamentos de adaptação locais - o que deve pressupor menos inteligência que no modelo da escolha racional - seja por meio de programas de papéis e rotinas, nos quais os atores seguem orientações institucionais e estruturais de ação (Scharpf, 2000; Vanberg, 2002).

Uma síntese preliminar dessa reflexão metateórica é que a questão da capacidade de integração das sociedades modernas é investigada, na análise da governança, por meio da micro-análise de configurações institucionais. Essa mesma questão é respondida pelas abordagens individualistas predominantemente como decisões individuais espontâneas à construção da ordem e pelas concepções holísticas da teoria dos sistemas em sua maioria com uma referência geral a macro-estruturas. O olhar se direciona tanto à lógica interna de atores (por exemplo, sua racionalidade e capacidade de ação), quanto aos arranjos institucionais, que estruturam sua ação. A teoria da governança pode assim ser interpretada como cibernética institucional, centrada em atores, que se vincula àquela idéia cibernética básica que influenciou a teoria sociológica dos sistemas dos anos 1960. A idéia básica afirma que a integração do sistema pressupõe determinados mecanismos sociais e políticos de condução. Estes, porém, são dissolvidos em atores, constelação de atores e arranjos 
institucionais. Problemas de adaptação ao meio ambiente social devem ser reconhecidos pelos atores, objetivos de adaptação devem ser determinados e recursos mobilizados a fim de solucionar problemas.

Aqui é esclarecedor considerar a história do conceito "governança" (Kenis e Schneider, 1996). A palavra "governança" remonta ao condutor (kybernêtês) dos antigos navios de guerra gregos; assim os filósofos gregos se referiam à condução do navio do Estado. Nisso se apóia a palavra artificial "cibernética", criada por Norbert Wiener. Correspondentes latinos são "gubernare" e "regere", que foram empregados tanto para a condução de um navio quanto do Estado. Disso derivam tanto o conceito inglês de "to govern" e francês "gouverner", quanto a palavra alemã "regieren". Deve-se observar também que o conceito "governance" é uma substantivação do verbo "to govern". Acentua-se assim os processos estatais de condução das posições de longo prazo. Por outro lado, e aí reside a inovação do conceito contemporâneo de governança, este não está mais limitado à condução estatal - o governo do Governo -, mas se aplica também ao governo, regulação e condução da sociedade por meio de instituições e atores sociais. Governança transcende com isso o conceito tradicional estatal e remete a formas adicionais de condução social (Figura 2).

\section{Figura 2}

Teoria do Estado e governança

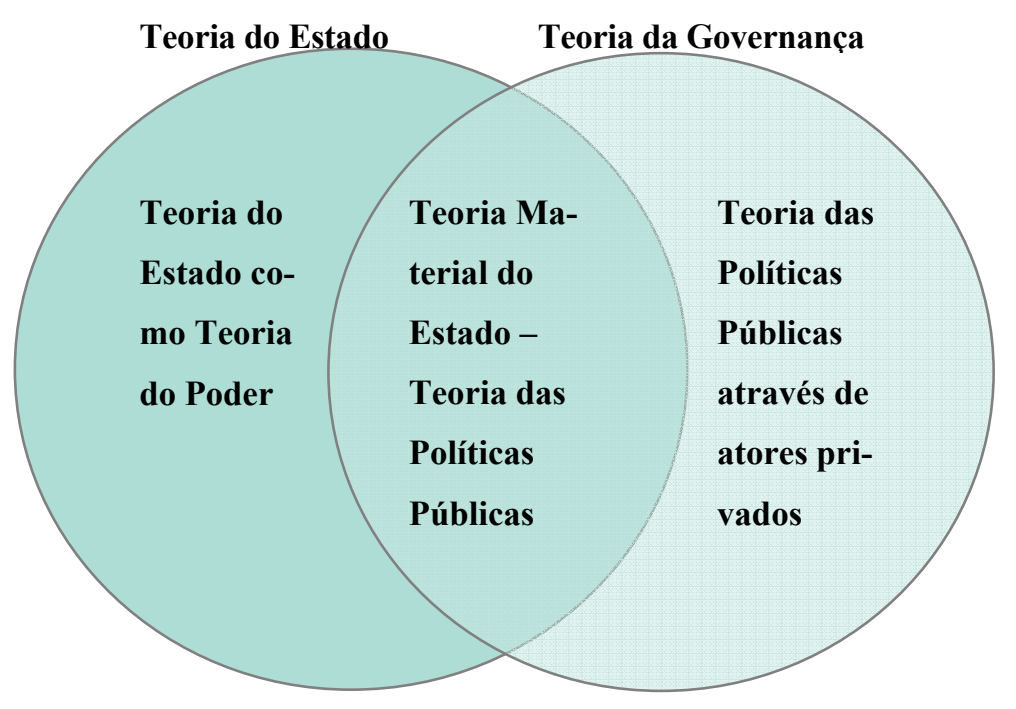


Como representado na Figura 2, a teoria da governança abrange com isso tanto a teoria material do Estado como também mecanismos sociais de integração e produção de ordem, como por exemplo, mecanismos decisórios em empresas (corporate governance) ou associações (associational governance) (Schneider, 2004a).

O que significa então concretamente micro-fundamentar um processo de condução a partir da teoria de atores? Em termos técnicos, condução é uma determinação de estados de um sistema por meio de uma definição externa de quantidades ou valores que determinam o comportamento de um sistema. Os elementos de um mecanismo de condução são, em geral, um dispositivo que determina a quantidade final de um sistema, assim como um mecanismo que transforma os objetivos em mudanças de estado (o assim chamado "ator" ou "atuador", ). Se a condução se encontra numa reação elétrica, que estabelece os possíveis desvios independentemente do estado final por meio de um sensor e que pode introduzir correções apropriadas com um mecanismo de ator, fala-se assim em regulação. Ocorre então um sistema cibernético em sentido estrito, no qual o controle é transformado através da relação entre objetivos endógenos e meio ambiente externo (Ashby, 1956; Bunge, 1987, p. 172-175). Na técnica, o termo "ator" ou "atuador" é reservado para um significado de condução técnica. Na eletrotécnica são caracterizados como conversor, que transforma sinais elétricos em movimento mecânico ou em outra quantidade ou valor físico. Na cibernética o conceito é mais abstrato, o qual se refere a um mecanismo que converte um sinal captado por um sensor em ações específicas, produzindo o estado desejado (Deutsch, 1966).

Adaptando-se para a teoria do ator, essa versão de condução pode ser utilizada também na ciência política. Atores "inteligentes" são ao mesmo tempo "sensores" e "atores". Tanto a formulação e determinação de dimensões finais políticas quanto a problematização e estabelecimento da diferença de deve/é pressupõe suas percepções, decisões e emprego de seus recursos. Como essas funções são resolvidas em sistemas políticos modernos depende

1 Aktuator (actuator em inglês, ou acionador automático) é um dispositivo em um aparelho que interfere na corrente de energia, colocando algo em ação automática. Por exemplo, tão logo apertamos o botão para iniciar a máquina de lavar roupas o tanque começa a ser preenchido de água. Esse tipo de máquina conta com um aparelho de medição que emite um sinal para interromper o fluxo de água quando esta atinge um determinado nível (agradeço aqui os esclarecimentos fornecidos por Björn Schreiner e Gilberto Capeletto [N. T.]. 
de padrões de diferenciação concretos. Por exemplo, uma divisão de trabalho pode predominar, em que atores sociais específicos são responsáveis, sobretudo, pela definição de um problema político, enquanto outros têm a tarefa de mobilizar e empregar recursos políticos específicos, que são necessários para a solução de problemas com base em decisões gerais correspondentes.

Essa perspectiva fundada na teoria dos atores se diferencia das abordagens institucionalistas e estruturalistas anteriores em razão de que os contextos de ação nos processos de condução e de regulação atuam sobre a ação "persistente" do ator. Os caminhos finais para o equilíbrio da sociedade não são fornecidos automaticamente pelo sistema, senão que devem ser procurados continuamente em contextos interativos de coordenação e sintonia. Assim, o controle ocorre sob condições em que atores possuem a autonomia de não reparar ou mesmo de ignorar os chamados "imperativos sistêmicos".

A produção do esforço de condução não precisa estar concentrada em nenhum sujeito de condução como, por exemplo, sobre o Estado ou uma direção de uma organização. Além disso, é possível conceber formas decentralizadas ou "policentradas" de condução política. A teoria da governança oferece uma série de possibilidades de catalogar a diversidade teórica desses mecanismos. Bastante conhecida é aquela classificação em que se distingue entre hierarquia e mercado como pontos extremos, e redes são concebidas como continuidade de formas híbridas ou intermediárias.

A análise da governança, com a distinção entre "alternativas estruturais discretas" (Williamson, 1996), tenta acima de tudo determinar empiricamente sobre quais configurações de relação do intercâmbio de informações e recursos entre atores se encontra uma definição de objetivos e uma mobilização conjunta de recursos. Sistemas institucionais de regras que definem capacidades de ação configuram com isso um sistema que produz e transmite impulsos de condução. Diferente da cibernética técnica, condução, no entanto, não é nenhum estabelecimento determinista de condições de conduta, mas, sobretudo estabelecimento de estímulos ou conformação cultural de ações individuais. Essas estruturas de governança podem se referir tanto a arranjos dentro das organizações quanto entre organizações. Uma típica estrutura de condução intra-organizacional é a hierarquia da organização. Esse é um mecanismo em que os objetivos da organização são definidos no topo e disseminados obrigatoriamente de cima para baixo por meio de correntes de ordens e 
controle centralizado de recursos. O mercado e a rede são padrões interorganizacionais típicos. Em qualquer uma dessas configurações trata-se de combinações complexas de instituições.

Nessa perspectiva, o mercado não é uma situação natural, mas uma configuração social que é altamente exigente em pré-requisitos institucionais. Assim, uma condição funcional fundamental é que seja garantido o direito à propriedade. Da mesma forma, mercados não funcionam sem infra-estruturas eficientes de informação. O mercado é acima de tudo um complexo sistema de intercâmbio econômico, que inclui além de fluxos de recursos, processos complexos de sinalização e produção de informações, que possibilita aquela lendária condução com a "mão invisível” (Williamson, 1994).

\section{Redes de políticas públicas como estruturas de governança}

Semelhante ao debate na sociologia e na economia institucional, também se observa na política há algum tempo contextos de condução policêntrica ou compartilhada (Klawitter, 1992; Willke, 1992). A partir da perspectiva da teoria de atores e da governança eles podem ser concebidos como redes de políticas públicas (Kenis e Schneider, 1991; Mayntz, 1996). Essas novas configurações políticas permitem, da mesma forma, pensar em rede industrial, na qual um produto final não é mais produzido por uma empresa integrada verticalmente, mas por uma cooperação de muitas empresas, que chegam a um consenso por meio de intenso intercâmbio de informações e que trocam ou combinam recursos complementares (Sydow, 1995). A "produção de políticas públicas" (Jansen e Schubert, 1995), a problematização e o processamento político de um problema social (Mayntz, 1982) não é mais um assunto exclusivo de uma hierarquia governamental e administrativa integrada, senão que se encontra em redes, nas quais estão envolvidas organizações tanto públicas quanto privadas.

Tais contextos podem ser observados em diferentes níveis e áreas da política - desde parcerias-público-privadas locais e áreas de política nacional até redes transnacionais de organizações, nas quais cooperam governos e organizações não-governamentais para tentar resolver problemas globais. Freqüentemente essas configurações modernas de formulação de políticas públicas são de tal maneira híbrida ou heterárquica, que os níveis não são 
sempre claramente separados, mas, ao contrário, atores de diferentes níveis com freqüência cooperam no processo de produção de políticas.

Já existe uma literatura considerável sobre este fenômeno de redes de políticas públicas. Esta permite não apenas uma ampla classificação teórica e de concepção de diferentes perspectivas e abordagens, como também algumas generalizações empíricas a respeito da estrutura de produção de políticas em democracias modernas.

1. O denominador mais comum de todas as análises de redes de políticas públicas é que a formulação de políticas públicas não é mais atribuída somente à ação do Estado enquanto ator singular e monolítico, mas resulta da interação de muitos atores distintos. A própria esfera estatal é entendida como um sistema de múltiplos atores.

2. Na formulação e implementação de políticas públicas, além de muitos atores públicos, estão envolvidos atores privados de distintos setores sociais e áreas.

3. O próprio conceito de rede se refere a vínculos diretos e indiretos relativamente duradouros, através dos quais os atores envolvidos estão integrados na formulação de políticas públicas.

4. Embora muitos atores estejam envolvidos direta e indiretamente na produção de políticas, existe entre eles diferença de poder e influência.

5. Posições de poder e influência não são determinadas somente através de status político-institucional formal, mas também por meio de vínculos informais (por exemplo, comunicação, intercâmbio de recursos, interação estratégica).

Redes de políticas públicas incorporam assim muitos atores distintos de diferentes sub-setores sociais e políticos no contexto de produção de uma política. Nesse caso as redes podem ser compreendidas certamente enquanto manifestações macroestruturais de sistemas políticos, nas quais interesses políticos e sociais são integrados no processo de políticas públicas de formas bastante distintas. Para se compreender esta lógica de condução é útil partir da conhecida compreensão do Estado de direito sobre a construção de vontades políticas, para a qual a formulação e implementação de políticas públicas é uma tarefa puramente estatal, em que o parlamento e o governo traduzem as preferências de seus eleitores em programas políticos. A partir desta perspectiva, interesses organizados possuem apenas importância indireta, como se exercessem de fora pressão ou influência sobre os atores públicos. De acordo com o modelo do Estado de direito as políticas são iniciadas no parlamento, que não apenas é completamente autônomo (seus membros são responsáveis 
apenas por suas consciências), mas que também a implementação de uma política está completamente sob controle da política e da administração. Muitas constituições no mundo estão orientadas por este ideal. Partidos, quando eventualmente mencionados, aparecem mais como uma aliança eleitoral e menos como uma grande organização política, que determina o processo político com seu próprio peso. Somente em poucas constituições políticas partidos, associações e sindicatos são mencionados enquanto elementos legítimos do processo político.

Esse ideal constitucional, no entanto, não corresponde à realidade política em praticamente nenhum dos países industrializados modernos. Tanto na formulação quanto na implementação de políticas não apenas atuam hoje muitos atores não-oficiais (como associações, por exemplo), quanto assumem freqüentemente uma posição central na definição de uma política. O complexo parlamentar e governamental previsto nas respectivas constituições seria hoje completamente sobrecarregado caso muitos dos demais atores sociais como partidos, grupos de interesse, institutos de pesquisa, autoridades administrativas e autarquias não se entendessem em redes informais de comunicação e cooperação, nem participassem na mobilização de recursos de políticas públicas, na coordenação de negociações políticas e na produção de políticas.

Em comparação ao modelo tradicional hierárquico de desenvolvimento de políticas, no qual a formulação e implementação de políticas era uma prerrogativa exclusiva do Executivo e do Legislativo, a formação de redes de políticas públicas pode ser vista como uma reação ao aumento da jurisdição da política estatal, à crescente interdependência e ao avançado acúmulo e concentração de recursos sociais em grandes organizações (atores corporativos). Em função de que recursos estatais e capacidades organizacionais não acompanham os efeitos dessa diferenciação social e os atores estatais são cada vez mais incapazes de garantir sozinhos os recursos necessários para a produção de políticas (formulação e implementação), o complexo parlamentar e governamental se torna em proporções cada vez maiores dependente da cooperação e da mobilização coletiva de recursos de atores não-estatais e privados. Contudo, como cooperação não se pode forçar, isso compele atores estatais à negociação com tais grupos sociais de poder (Scharpf, 1992).

Por trás desta cambiante relação de forças entre Estado e sociedade, redes de políticas públicas podem ser encaradas assim como novas formas de 
condução política, como é, por exemplo, apontado por Kenis e Schneider (Kenis e Schneider, 1991, p. 41): "Redes de políticas públicas são novas formas de governança política que reflete uma relação modificada entre Estado e sociedade [...] Redes de políticas públicas são mecanismos de mobilização de recursos políticos em situações em que a capacidade de tomada de decisão, de formulação e implementação de programas é amplamente distribuída ou dispersa entre atores públicos e privados." Para a realização de suas responsabilidades cada vez mais diferenciadas, o Estado é obrigado a adquirir os recursos políticos necessários por meio de um processo de intercâmbio com atores sociais, a deslocar as tarefas para unidades sociais de processamento (auto-regulação setorial parcial ou completa) ou produzir conjuntamente políticas em cooperação com atores sociais por meio de uma divisão do trabalho.

Com isso ocorre com freqüência arranjos em que as fronteiras entre privado e público crescentemente se confundem e as estruturas hierárquicas de autoridade não mais se propagam. Tais redes podem se formar ad hoc e se referir apenas a um tema conjuntural. Sobretudo na Alemanha predominam, entretanto, em muitos setores estruturas permanentes de relação, nos quais atores relevantes de redes dispõem de relações de comunicação e cooperação no processo político. Isso produz confiança e facilita assim negociações e construção de acordos. Nessas relações horizontais de produção de políticas públicas participam todos aqueles atores que influenciam de maneira direta ou indireta o desenvolvimento de uma política.

Para efeitos de síntese, a especificidade das relações organizadas de produção de políticas através de redes de políticas públicas pode ser localizada em um eixo bidimensional, que se divide ao longo dos eixos "forma de coordenação" e "status social" dos atores envolvidos. O eixo forma de coordenação e condução contém, por um lado, o ponto extremo de uma configuração, na qual uma política específica é determinada por um único ator (principal) e formulado e convertido em relações de autoridade (hierarquia). De outro lado, encontra-se o ponto extremo em que a política se forma a partir da ação espontânea, não-planejada e inconsciente de muitos atores persistentes e dispersos (mercado). Redes, ao contrário, estão entre esses dois pontos extremos onde se encontram os contextos de interação, nos quais o número de atores envolvidos em uma política fica visível e em que os atores estão informados sobre seus respectivos interesses, ajustam ou negociam sua ação 
conjunta, e também podem por fim estabelecer cooperação de longo prazo. A dimensão do status social refere-se ao eixo entre privado e público, que pode se referir tanto ao controle da ação quanto à produção de cada um dos atores corporativos. Controle público de uma organização significa que a ação da organização é controlada por meio de um mecanismo de decisão, no qual todos direta ou indiretamente participam e ninguém está excluído. Análogo a isso é que a produção pública de uma organização é caracterizada pelo fato de que (em princípio) ninguém está excluído do seu uso ou consumo. Organizações públicas são, nesse sentido, potencialmente controladas por todos (pressupondo-se evidentemente uma estrutura política democrática), e da mesma forma sua produção é também potencialmente direcionada a todos os membros da sociedade.

\section{Análise quantitativa de redes de políticas públicas}

As generalizações listadas acima, a partir da extensa literatura sobre redes de políticas públicas, se deixam corroborar, sobretudo por meio de estudos quantitativos, que nas últimas duas décadas empregam técnicas formais a fim de delimitar de maneira sistemática os sistemas de atores de redes correspondentes e medir empiricamente a rede de relações políticas e analisá-los com métodos formais. Nos próximos parágrafos será apresentada uma pequena, mas informativa, amostra de tais análises quantitativas de redes de políticas públicas e com isso será investigado a dimensão que possui cada uma das redes e que proporção assumem nessas redes os interesses econômicos em especial - por um lado por meio de associações e por outro lado através da participação direta de grandes empresas.

A Tabela 1 lista uma série de análises quantitativas de redes de políticas públicas nas quais são analisados distintos setores ou processos de políticas públicas em alguns países. Os autores nomeados na primeira coluna correspondem aos estudos mencionados na referência bibliográfica. Embora nesse período tenham sido realizadas algumas pesquisas sobre redes de políticas públicas ao nível da União Européia (Pappi e Henning, 1999), a listagem a seguir se limita à análise de sistemas nacionais. A lista compreende: (1) A comparação dos setores de políticas de energia e saúde nos Estados Unidos (Laumann e Knoke, 1987) relativos ao final dos anos 1970 e início dos anos 1980; (2) análises de redes de processos de redes de políticas públicas especí- 
ficas na legislação sobre químicos no início dos anos 1980 (Schneider, 1988) e a introdução do sistema alemão de dados em tela de TV em meados dos anos 1980 (Schneider, 1989, 1993); (3) a análise da primeira reforma do setor de telecomunicações na Alemanha por volta do fim dos anos 1980 (Schneider e Werle, 1991); (4) uma comparação intersetorial das redes nos setores de política agrícola, de energia, saúde e trabalho (Heinz; Laumann; Nelson; Salisbury, 1993); (5) uma comparação internacional do setor de políticas de trabalho nos Estados Unidos, Alemanha e Japão no início dos anos 1990 (Knoke; Pappi; Broadbent; Tsujinaka, 1996); (6) uma análise de políticas de um processo de decisão de política agrícola na Suíça no final dos anos 1980 (Sciarini, 1996); (7) uma análise de rede no setor de políticas de saúde e políticas sociais na Finlândia (Mattila, 1994, 1999); (8) uma comparação intersetorial de setores de políticas no Canadá referentes à desregulamentação/liberalização do setor aéreo, do comércio e dos bancos assim como a promoção da educação (Howlett, 2002). Esta não é uma análise de redes quantitativa em sentido estrito porque ela se baseia na avaliação de literatura secundária; ela compreende, contudo, uma delimitação e categorização sistemáticas dos atores envolvidos. (9) A análise de dois processos de privatização na Alemanha (Raab, 2002).

Esses nove estudos contêm informações mais ou menos sistemáticas sobre 20 setores de políticas que estão listados na Tabela 1. Ao lado do tamanho total das redes também é listada a extensão de atores sociais da economia (associações econômicas, empresas) em percentual. Uma vez que os estudos empregam distintos procedimentos de delimitação de redes e de identificação de atores, é importante corrigir algumas populações para elevar a possibilidade de comparação. Em um estudo é mencionada explicitamente apenas a participação de atores privados (Heinz; Laumann; Nelson; Salisbury, 1993), e em outros estudos (Lauman e Knoke, 1987; Knoke; Pappi; Broadbent e Tsujinaka, 1996), algumas unidades organizacionais formais são subdivididas (por exemplo, comissões ou departamentos), o que inflaciona a população de atores. Por essa razão, na coluna 2 estão apresentados os tamanhos corrigidos, através dos quais se consegue melhorar a comparação. A coluna 3 apresenta o percentual de associações e empresas juntas nas redes de políticas públicas. 
Tabela 1

Análises de redes, tamanho das redes e a participação de atores econômicos

\begin{tabular}{|c|c|c|c|c|c|}
\hline Análises & País & $\begin{array}{c}\text { Setor / } \\
\text { Processos } \\
\text { de políticas }\end{array}$ & Número & $\begin{array}{l}\text { Número } \\
\text { corrigido }\end{array}$ & $\begin{array}{c}\text { Atores } \\
\text { econ. } \\
\text { em \% }\end{array}$ \\
\hline & & & 1 & 2 & 3 \\
\hline \multirow{2}{*}{$\begin{array}{c}\text { Lauman e } \\
\text { Knoke, } \\
1987\end{array}$} & \multirow[t]{2}{*}{ EUA } & Energia & 198 & 182 & 63 \\
\hline & & Saúde & 135 & 115 & 15 \\
\hline $\begin{array}{c}\text { Schneider, } \\
1988\end{array}$ & Alemanha & Químicos & 26 & 26 & 12 \\
\hline $\begin{array}{c}\text { Schneider, } \\
1989\end{array}$ & Alemanha & Videotexto & 43 & 43 & 60 \\
\hline $\begin{array}{l}\text { Schneider e } \\
\text { Werle } 1991 \\
\end{array}$ & Alemanha & Telecomunicações & 36 & 36 & 50 \\
\hline \multirow{4}{*}{$\begin{array}{l}\text { Heinz et. } \\
\text { al., } 1993\end{array}$} & \multirow[t]{4}{*}{ EUA } & Agricultura & 80 & 105 & 54 \\
\hline & & Energia & 76 & 102 & 57 \\
\hline & & Saúde & 81 & 105 & 24 \\
\hline & & Trabalho & 74 & 99 & 25 \\
\hline \multirow{3}{*}{$\begin{array}{l}\text { Pappi et. } \\
\text { al., } 1995 \\
\text { Knoke et } \\
\text { al., } 1996\end{array}$} & Alemanha & Trabalho & 126 & 112 & 21 \\
\hline & EUA & Trabalho & 117 & 117 & 22 \\
\hline & Japão & Trabalho & 122 & 122 & 30 \\
\hline $\begin{array}{c}\text { Sciarini, } \\
1996\end{array}$ & Suíça & Agricultura & 28 & 28 & 46 \\
\hline $\begin{array}{c}\text { Mattila, } \\
1994 \\
\end{array}$ & Finlândia & Saúde e Social & 45 & 45 & 4 \\
\hline \multirow{4}{*}{$\begin{array}{c}\text { Howlett, } \\
2002\end{array}$} & \multirow{4}{*}{$\begin{array}{c}\text { Canadá } \\
2000\end{array}$} & Aviação & 55 & 55 & 64 \\
\hline & & Comércio & 46 & 46 & 33 \\
\hline & & Educação & 102 & 102 & 23 \\
\hline & & Bancos & 137 & 137 & 61 \\
\hline \multirow[t]{2}{*}{ Raab, 2002} & \multirow[t]{2}{*}{ Alemanha } & Indústria naval & 232 & 23 & 22 \\
\hline & & $\begin{array}{l}\text { Indústria } \\
\text { siderúrgica }\end{array}$ & 182 & 18 & 22 \\
\hline
\end{tabular}


A meta-análise da literatura quantitativa sobre redes de políticas públicas possibilita uma série de observações: (1) há uma evidência expressiva de que os sistemas de atores nas políticas em todos os países e setores são constituídos não de poucos, mas de muitos atores. (2) No que se refere ao status institucional dos atores, a participação dos atores privados oscila consideravelmente. O percentual de atores econômicos fica entre 4\% e 64\% (média de 35\%). (3) Em muitos países, além das associações, muitas grandes empresas também participam fortemente no processo de formulação de políticas.

Embora seja possível obter generalizações desse material, seria prematuro tirar conclusões específicas, por exemplo, quanto à forma, ou seja, de que a diferença de tamanho ou participação e posições de atores privados seriam explicáveis por características específicas de países ou políticas. Como já mencionado, as análises utilizam distintos procedimentos de delimitação de redes e identificação de atores. Nesse sentido Laumann e Knoke (1987) oferecem o mais alto grau de comparação internacional, enquanto que a comparatibilidade intersetorial do estudo de Knoke et al. (1996) é a mais alta. Mas mesmo nessas excelentes análises empíricas existem problemas de comparação. Apesar dessas limitações se pode afirmar, contudo, com grande segurança, com base nesse resumo de que a política moderna está fundada em sistemas multi-atores, e de que grande parte dos participantes vem do setor privado.

O escopo desse resumo iria se romper se, com base em alguns dados sobre redes, fosse possível uma estrutura comparativa detalhada. Contudo, com ajuda de três redes de políticas públicas pode ser ilustrada a diversidade com que uma rede pode ser estruturada e como categorias distintas de atores estão posicionados. Aqui serão representados graficamente os 20 a 25 atores mais influentes e suas redes de comunicação nas áreas de políticas de legislação do setor químico (Schneider, 1988), na reforma das telecomunicações (Schneider e Werle, 1991) e no setor de políticas de energia norte-americano (Laumann e Knoke, 1987). Distintas categorias de atores como organizações estatais, partidos, associações econômicas e empresas são representadas em distintas formas e cores. Atores representados em círculos mais escuros são organizações estatais (governo e administração), círculos em cinza mais claros são partidos políticos, círculos em tom cinza escuro-claro são sindicatos, quadrados são associações, losangos são empresas e círculos com cinza de tom intermediário são associações ambientais. O posicionamento dos atores no espaço expressa a centralidade na rede de intercâmbio de informação. 
Semelhante a um alvo, os atores estão posicionados mais no centro quanto mais próximos estiverem do ponto no meio. Essa visualização foi construída com o programa de computador Visone, desenvolvido por um grupo de trabalho coordenado por Ulrik Brandes na Universidade de Konstanz (Brandes; Raab e Wagner, 2001). O critério empregado aqui é o vetor de autocentralidade, a partir do qual um nó é mais central quanto mais vínculos possuir com outros nós igualmente centrais.

A primeira rede apresentada aqui representa o núcleo dos 25 atores mais influentes na política norte-americana de energia e sua estrutura de comunicação no início dos anos 1980. Baseia-se em dados do estudo já citado várias vezes de Laumann e Knoke (1987). Na Figura 3 está representada a rede de intercâmbio de informação entre essas 25 organizações, que obtiveram a mais alta reputação quanto à influência no estudo da rede. Os atores mais centrais são aqui o Ministério da Energia (MoE), a Casa Branca (White House) assim como o Departamento de Gestão e Orçamento (OMB) (Figura 3).

Ao lado dos Republicanos no Congresso, várias associações econômicas pertencem ao círculo seguinte de atores centrais. Vale notar aqui que também algumas grandes empresas, especialmente do setor de petróleo, assumem uma posição importante. Associações ambientais e sindicatos se situam mais na periferia entre os 25 atores mais influentes do setor de políticas de energia.

Diferenças importantes no setor de legislação do setor químico (23 atores com a mais alta reputação de influência ${ }^{2}$ ) são que, em primeiro lugar, uma associação econômica (a Associação da Indústria Química) assume uma posição bastante central na estrutura de comunicação - tão importante quanto os atores estatais mais influentes (Ministério da Saúde e Ministério do Trabalho e suas repartições especiais). Em segundo lugar deve-se reconhecer que na Alemanha os sindicatos assumem uma posição visivelmente mais importante que os sindicatos nos Estados Unidos. Em terceiro lugar, organizações internacionais como OCDE e União Européia têm uma posição nada insignificante na rede. Uma semelhança com os Estados Unidos é que não tanto o

Uma vez que muitos atores demonstraram uma mesma reputação na posição 25 e como não se dispunha de qualquer dado sobre intercâmbio de informação sobre o Congresso, foi representada uma rede de apenas 23 atores. 
Legislativo, mas os atores do Executivo é que determinam o processo político de comunicação (Figura 4).

\section{Figura 3}

A rede norte-americana do setor de energia

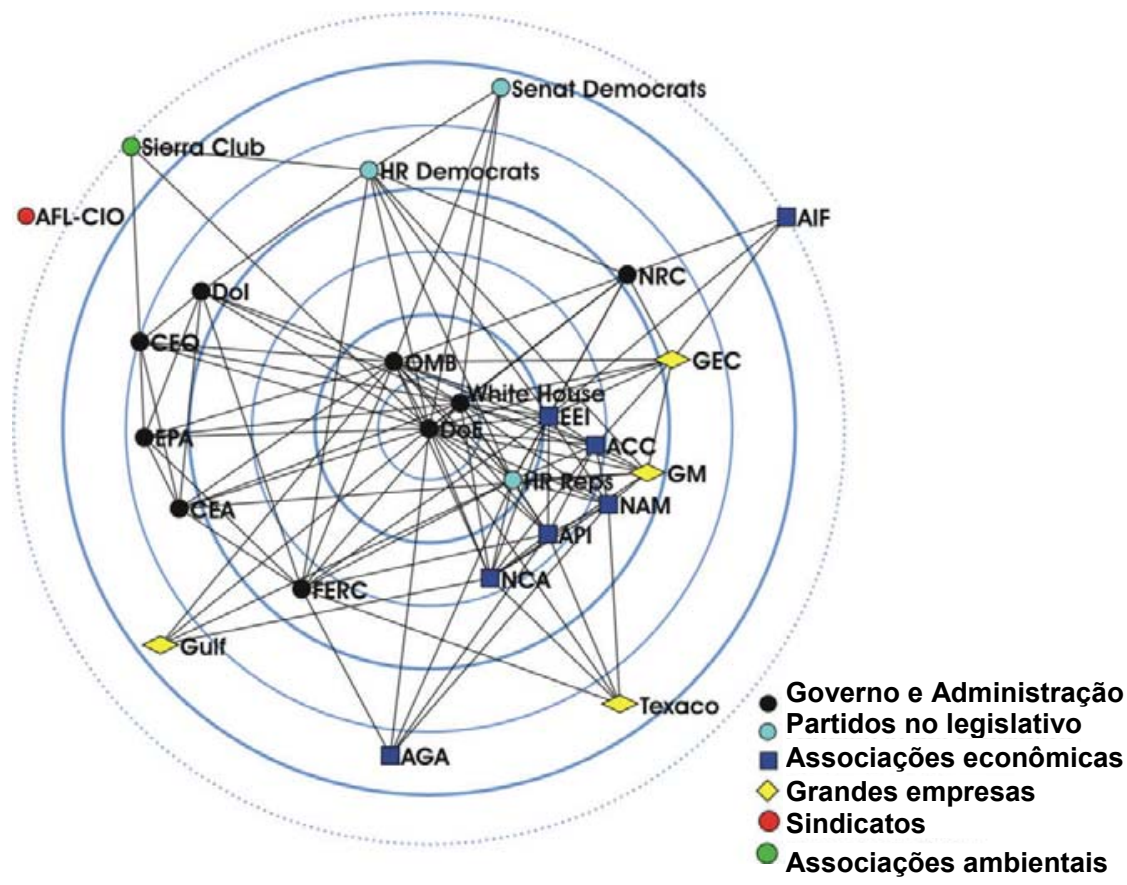




\section{Figura 4}

A rede alemã de políticas de controle químico

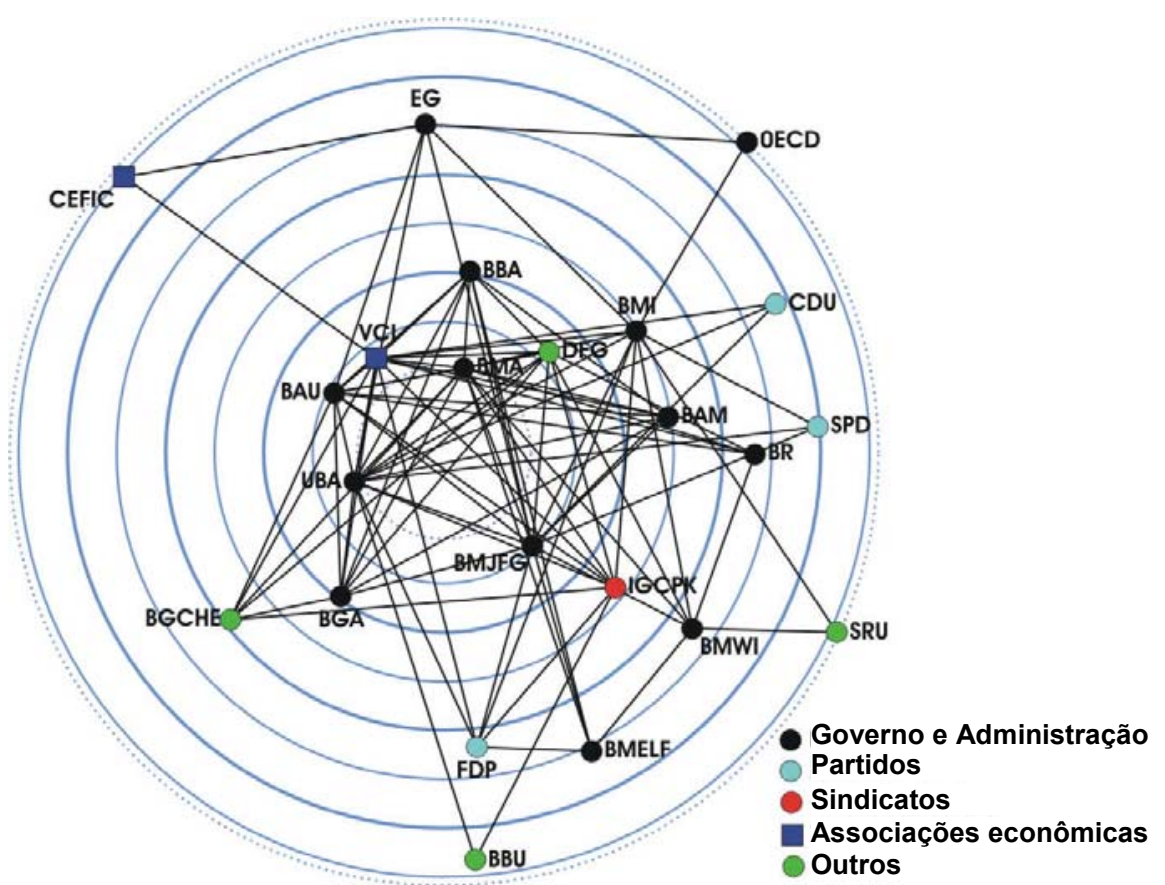

A terceira rede apresentada aqui representa a estrutura de comunicação dos 24 atores mais influentes da primeira reforma das telecomunicações na Alemanha no final dos anos 1990 (Figura 5). 


\section{Figura 5}

A rede de políticas públicas da reforma das telecomunicações alemãs

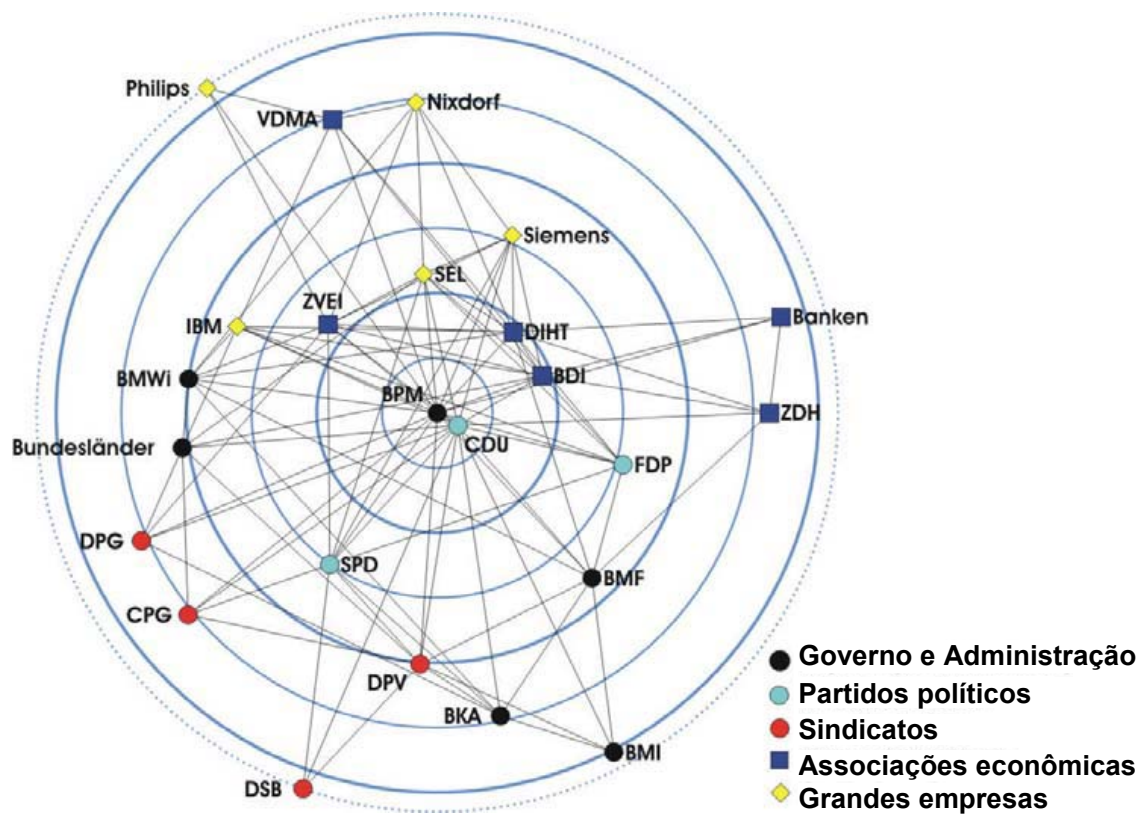

Como esperado também aqui o ator executivo (Ministério das Comunicações) responsável por este setor de política está no centro. Contudo, surpreendente aqui é que bem ao lado partidos políticos e uma série de associações econômicas e grandes empresas assumem igualmente posições importantes nos círculos centrais. Além disso, chama a atenção que os funcionários do antigo correio não foram representados apenas pelo sindicato dos correios (DPG), mas também por várias outras associações menores. Também esta imagem mostra no seu conjunto que o processo de formulação de políticas foi mantido por uma constelação de multiatores, na qual estão incluídos interesses de distintos setores sociais. 


\section{O conceito de rede de políticas públicas como resultado de três processos de mudança}

Uma questão interessante é por que o pensamento de redes na análise de políticas públicas se difundiu somente nas últimas décadas, embora a metáfora da rede tenha sido utilizada por teóricos pluralistas do Estado e da sociedade já no início do século XX. Isso deve ser atribuído a motivos internos à ciência, que estão localizados exclusivamente na dinâmica teórica das ciências sociais, ou a formação de teorias reage também a mudanças e progressos sociais reais, sem que seja interpretado como sendo "reflexo" no sentido de teorias epistemológicas reflexivas. A seguir será defendida a tese de que a inovação da concepção de "redes de políticas públicas" foi promovida decisivamente por três dinâmicas de desenvolvimento, que se referem a (1) mudanças sociais contemporâneas, (2) a uma tendência específica da própria dinâmica do desenvolvimento teórico das ciências sociais e (3) finalmente, também ao surgimento de "novas tecnologias do conhecimento" (Kenis e Schneider, 1991).

Como já apresentado, o conceito de redes de políticas públicas implica uma visão da realidade na qual as políticas públicas não são formuladas e implementadas apenas por um único ator público (o Estado), mas que também atores privados ou sociais participam nesse processo de produção e oferta de bens públicos. Além disso, está compreendido aí que o Estado não é mais entendido como uma "hierarquia pública" sempre integrada, senão que ele próprio representa uma rede de organizações relativamente autônomas.

Ambos os aspectos não são teoricamente novos. Sobretudo a idéia da participação de grupos privados nas políticas públicas é um pensamento central da velha teoria pluralista de mais de 100 anos. Nesse contexto, a idéia de um Estado fragmentado como reservatório de grupos de interesses já estava contida nas teorias de Arthur Bentley (Bentley, 1967) e Harold Laski (Laski, 1916) do início do século XX. Novo porém é que desde o último terço do século XX abordagens de teorias de influência simplificadas e instrumentalizadas sobre a relação Estado e sociedade, na qual grupos sociais instrumentalizam ou exercem pressão externa sobre ele, foram superadas e substituídas por formulações em que a relação entre Estado e sociedade foram concebidas mais como dependência funcional ou interdependência baseada nos recursos (Offe, 1972). Uma versão específica disso é a teoria do neocorporativismo, 
na qual são acentuadas em especial as relações de troca e negociação entre Estado e poderosos interesses sociais organizados (Schmitter e Lehmbruch, 1979; Streeck e Kenworthy, 2004).

Embora a teoria neocorporativista contenha idéias diferenciadas sobre as relações interativas entre Estado e interesses organizados, ela não dispõe ainda - apesar de várias tentativas (Cawson, 1978, Schmitter, 1985) - de qualquer teoria do Estado elaborada, que faça asserções sobre as condições constitutivas estruturais e tendências de transformação estatal e sobretudo que pudesse abordar o problema da fragmentação interna. Isso é problematizado desde os anos 1970 e 1980 muito mais nas pesquisas organizacionais alemãs e norte-americanas das ciências administrativas (Mayntz e Scharpf, 1975; Milward e Wamsley, 1984; McCool, 1998), como também nas teorias de Estado francesas e italianas, as quais se referem a subunidades relativamente autônomas do governo e da administração (Poulantzas, 1978; Bobbio, 1987).

Uma tendência central na mudança do setor estatal é sem dúvida a expansão do dramático intervencionismo estatal desde os anos 1960, que se mostra tanto na expansão qualitativa do espectro de responsabilidades estatais quanto também no crescimento quantitativo do Estado. Em dimensões crescentes ocorre uma progressiva diferenciação interna do setor público que não é sem conseqüências para o "campo organizacional" interno do Estado (Janning, 1998). Com a diferenciação ocorre uma crescente autonomização de algumas repartições, que são por um lado intencionais e fundamentados formal e institucionalmente. Por outro lado, com base simplesmente nos recursos resulta em conseqüências não-intencionais de ação do processo de expansão do Estado. Vincula-se a isso uma crescente especialização e dispersão de recursos no espaço social e com isso uma autonomização de partes constitutivas da sociedade e de unidades organizadas. Tanto a teoria sociológica quanto a teoria econômica da organização mostra que organizações ganham em autonomia em razão da progressiva diferenciação e especialização funcional.

No interior do Estado isso faz com que o controle hierárquico extensivo se torne ineficaz. Além disso, nas últimas décadas a unidade administrativa também foi institucionalmente dissolvida em múltiplos centros. Ao lado da administração tradicional existem agora instituições públicas, empresas públicas e agências reguladoras independentes - sem falar das formas mistas de organização semi e para-estatais. Também a sociedade se transformou a tal 
ponto de o Estado não mais se defrontar somente com indivíduos, mas também com um número crescente de atores corporativos, organizações formais, portanto, que marcam a face da sociedade moderna (Coleman, 1974; Perrow, 1996). No mesmo período, no qual se observa em todos os países industrializados avançados um rápido crescimento do Estado, crescem também as grandes organizações, em especial grandes empresas e associações, que organizam os mais diferentes interesses.

Igualmente acentuada nesse período é a expansão além-fronteiras de firmas e o crescimento de organizações internacionais, para as quais os conceitos internacionalização e globalização se impuseram. Esses processos provocam uma superação das fronteiras nacionais e uma transnacionalização das políticas públicas (Scharpf, 1992; Mayntz, 2001). A conseqüência é que as estruturas de dependência do Estado em relação a atores sociais são sobrepostas agora por estruturas internacionais de interdependência, nas quais a soberania dos Estados nacionais também é desafiada em nível internacional. $\mathrm{O}$ Estado nacional isolado pode cada vez menos conduzir e controlar sozinho tanto dentro do seu território quanto também no sistema global de Estados, e é compelido à negociação, intercâmbio, coordenação e cooperação.

Uma outra importante transformação do Estado e da sociedade está na “digitalização". Com a Era Digital, que se iniciou com a invenção do microship (circuito integrado) no início dos anos 1970 e que avança sobre o século XXI, Estado e sociedade são reestruturados de forma profunda. Digitalização remete a um forte potencial de alargamento e economização da comunicação, o que na minha opinião representa um importante fator - certamente não o único - do processo contemporâneo de globalização. Mesmo as revoluções das comunicações, provocadas pelo telégrafo e telefone, foram importantes fatores tecnológicos que impulsionaram o crescimento nacional e internacional de grandes organizações desde o fim do século XIX. Com a digitalização ocorreu uma aceleração jamais vista tanto da expansão territorial quanto do crescimento da dimensão das organizações. A atividade mundial das atuais mega-empresas não seria possível sem uma rede internacional de computadores, como também não seria possível a atual mobilidade de capital do sistema financeiro internacional. A digitalização possibilita e acelera a superação de fronteiras transnacionais e a expansão de atores corporativos (Schneider, 2004c). 
Ao lado disso, a digitalização teve também um outro efeito: ela acelera através da técnica de computador - a difusão do pensamento relacional e sistêmico nas ciências sociais e, assim, atua também como uma nova "tecnologia do conhecimento". Quem pensa em rede supera o pensamento convencional pelo menos em duas dimensões. Um teórico da rede pensa a sociedade enquanto uma imagem complexa, na qual - diferentemente do individualismo - a sociedade não aparece apenas como um agregado de indivíduos independentes, mas como um contexto integrado, sistêmico, que se constitui de muitos elementos (nós) e relações entre esses nós. O teórico da rede não capitula diante da realidade complexa, a qual ele se refere ao fim e ao cabo a um todo que não é passível de análise, em que tudo está conectado com tudo. Ele decompõe e disseca o emaranhado social e político, no qual ele destaca, por exemplo, posições relacionais e zonas de concentração na rede.

A idéia de rede é uma orientação analítica fundamental, que se mostra em muitas novas teorias e programas de pesquisa, como por exemplo na teoria sociológica das relações interorganizacionais, na análise de redes sociais e desde algum tempo também na teoria da complexidade. Aqui se recorre em regra a métodos matemáticos estruturais e relacionais como também a algoritmos grafo-teóricos da informática. Isso significa atualmente dentre outras coisas que surge uma nova ciência transdisciplinar da rede, que combina pesquisas das ciências naturais e das ciências sociais (Barabási, 2002; Watts, 2003).

\section{Conclusão: implicações para uma moderna teoria do Estado e da democracia}

Diferenciação funcional, crescimento de atores corporativos e superação de fronteiras nacionais fizeram com que um número crescente de atores estatais e privados "se envolvessem" decisivamente na formulação e implementação de políticas públicas, o que não está previsto na maioria das constituições do mundo, pelo menos nos modelos liberais de democracia. Se governos querem formular e implementar programas eficazes então são obrigados a informar informalmente ou pelo menos considerar os interesses daqueles atores sociais que possuem recursos específicos relevantes para as políticas no processo de decisão. A partir da perspectiva da teoria da democracia as novas formas de governança não estão desprovidas de problemas (Papadopo- 
lous, 2004). Como novas formas de “democracia pós-parlamentar" (Burns, 1994; Benz, 1998) elas distorcem a representação democrática, em que atores com maior potencial de troca podem conseguir vantagens no processo público de decisão. Elas também confundem responsabilidades e conduzem à intransparência não-democrática (Schneider, 1999, 2000).

Uma questão até hoje não respondida conclusivamente é como essa deficiência de democracia das redes de políticas públicas e sistemas de negociação pode ser tratada. Existe a sugestão de combinar as arenas de negociação com arenas de democracia direta para reduzir assim o déficit de legitimação (Benz, 1998). De acordo com essa idéia, nas redes de políticas públicas e nas arenas parlamentares poderiam ser negociados e decididos sobre os mesmos temas e num segundo passo os cidadãos decidiriam diretamente entre alternativas negociadas de solução. Ainda que com isso resultados de negociação democrática fossem sem dúvida melhor legitimadas isso iria minar ainda mais a posição do parlamento. Uma solução convincente parece estar mais no fortalecimento do parlamento, a fim de que este último bastião do controle obrigatório do bem comum possa executar suas competências da melhor forma. Além disso, poderia, de um lado, aumentar a capacidade de processamento de informações parlamentares e, de outro lado, aumentar as competências dessa instituição. Apesar do conhecimento de que o conteúdo de decisões políticas é influenciado "inoficialmente" por muitos atores, deve haver um competente "controle no fim da linha", que esteja em condição de examinar as soluções previamente acordadas e rejeitá-las após ponderar todas as vantagens e desvantagens para o bem comum (Schneider, 2000). Mesmo que se encare ceticamente as capacidades cognitivas dos parlamentares para isso, deve-se esperar uma tal competência ainda menos de procedimentos plebiscitários, considerando as limitações de racionalidade descritas.

\section{Referências}

ALMOND, Gabriel A.; BINGHAM POWELL, G. Comparative politics. A developmental approach. Boston: Little, Brown and Company, 1966.

ASHBY, W. Ross. An introduction to cybernetics. London: Chapman \& Hall, 1956.

BARABÁSI, Albert-László. Linked: The new science of networks. Cambridge: Perseus, 2002. 
BENTLEY, Arthur F. The process of government: a study of social pressure. Cambridge: Harvard University Press, 1967.

BENZ, Arthur. Postparlamentarische Demokratie? Demokratische Legitimation im kooperativen Staat. In: Michael Greven (ed.). Demokratie - Eine Kultur des Westens? Opladen: Leske + Budrich, 1998, p. 201-222.

(ed.). Governance - Regieren in komplexen Regelsystemen - Eine Einführung. Wiesbaden: VS Verlag für Sozialwissenschaft, 2004.

BOBBIO, Noberto. The future of democracy: a defence of the rules of the game. Cambridge: Polity Press, 1987.

BRANDES, Ulrik; RAAB, Jörg; WAGNER, Dorothea. Exploring network visualization: simultaneous display of actor status and connections. Journal of social structure, 2, 2001, p. 1-28.

BUNGE, Mario. Kausalität, Geschichte und Probleme. Tübingen: Mohr, 1987.

_. Finding philosophy in social science. New Haven: Yale University Press, 1996.

BURNS, Tom R. Post-Parlamentary democracy. Sacralities, Contradictions and transitions of Modernity. In: MONGARDINI, Carloand; RUINI, Marieli (eds.). Religio. ruolo del sacro, coesione sociale e nuove forme di solidarietà nella società contemporana. Roma: Bulzoni, 1994.

CAWSON, Alan. Pluralism, corporatism and the role of the state. Government and opposition, 13, 1978, p. 178-198.

COLEMAN, James S. Power and the structure of society. New York: Norton, 1974.

Foundations of social theory. Cambridge: Harvard University Press, 1990.

DEUTSCH, Karl W. The nerves of government: models of political communication and control. New York: Free Press, 1996.

EASTON, David. A systems analysis of political life. New York: Wiley, 1967.

ELSTER, Jon. Marxism, functionalism, and game theory. The case for methodological individualism. Theory and society, 11, 1982, p. 453-482.

FRIEDRICH, Carl J. Constitutional government and democracy: theory and practice in Europe and America. New York: Blaisdell, 1950.

GROTE, Jürgen R.; GBIKPI, Bernard (eds.). Participatory governance. Political and societal implications. Opladen: Leske + Budrich, 2002.

HEINZ, John P. et al. The hollow core: private interests in national policy making. Cambridge: Harvard Univ. Press, 1993.

HOWLETT, Michael. Do networks matter - linking policy network structure to policy outcomes - evidence from 4 canadian policy sectors 1990-2000. Canadian journal of Political Science - Revue canadienne de Science Politique, 35, 2002, p. 235-267. 
JANNING, Frank. Das politische Organisationsfeld. Wiesbaden: Westdeutscher Verlag, 1998.

JANSEN, Dorothea; SCHUBERT, Klaus. Netzwerke und Politikproduktion: Konzepte, Methoden, Perspektiven. Marburg: Schüren, 1995.

KENIS, Patrick; SCHNEIDER, Volker (eds.). Organisation und Netzwerk. Institutionelle Steuerung in Wirtschaft und Politik. Frankfurt: Campus, 1996.

. Policy Networks and Policy Analysis: Scrutinizing a New Analytical Toolbox. Frankfurt: Campus, 1991, 25-59. In: MARIN, Bernd; MAYNTZ, Renate (eds.). Policy Networks. Empirical Evidence and Theoretical Considerations. Frankfurt: Campus, 1991, p. 25-59.

KLAWITTER, Jörg. Staatstheorie als Steuerungstheorie? Vorüberlegungen im Hinblick auf ein staatstheoretisch fundiertes, akteurzentriertes und verhandlungsorientiertes Netzwerk polyzentrischer Gesellschaften. In: HEINRICH BUßHOFF (ed.). Politische Steuerung. Steuerbarkeit und Steuerungsfähigkeit. Beiträge zur Grundlagendiskussion. Baden-Baden: Nomos, 1992, p. 193-239.

KNOKE, David, et al. Comparing policy networks: labor politics in the U.S. Germany, and Japan. Cambridge: Cambridge University Press, 1996.

LASKI, Harold J. The Sovereignty of the State. The Journal of Philosophy, Psychology and Scientific Methods, 1916, 13, p. 85-97.

LAUMANN, Edward O.; KNOKE, David. The organizational state. social choice in national policy domains. Madison: University of Wisconsin Press, 1987.

MATTILA, Mikko. Hierarchy or competition? The interest representation network of organized labour in finnish social and health policy making. Acta Sociologica 37, 1994.

- The structure of policy networks: an analysis of political decision making network in Finland. Unpuplished Paper, 1999. Internet: http://www.valt.helsinki.fi/staff/mmattila/workpape.htm.

MAYNTZ, Renate. Problemverarbeitung durch das politisch administrative System. In: HESSE, Joachim (ed.). Politikwissenschaft und Verwaltungswissenschaft. Opladen: Westdeutscher Verlag, 1982, 74-89.

. Policy-Netzwerke und die Logik von Verhandlungssystemen. In: KENIS, Patrick; SCHNEIDER, Volker (eds.). Organisation und Netzwerk. Institutionelle Steuerung in Wirtschaft und Politik. Frankfurt: Campus, 1996, 471-496.

. Politikwissenschaft in einer entgrenzten Welt. In: LANDFRIED, Christine (ed.). Politik in einer entgrenzten Welt. Köln: Verlag Wissenschaft und Politik, 2004, p. 29-47.

. Governance theory als fortentwickelte Steuerungstheorie? MPIfG Working Paper, 2004. Internet: http://www.mpi-fg-koeln.mpg.de/pu/workpap/wp04-1/wp041.html. 
; SCHARPF, Fritz W. Policy-making in the German federal bureaucracy. Amsterdam: Elsevier, 1975.

; SCHARPF, Fritz W. Der Ansatz des akteurzentrierten Institutionalismus. In: MAYNTZ, Renate; SCHARPF, Fritz W. (eds.). Gesellschaftliche Selbstregelung und politische Steuerung. Frankfurt: Campus, 1995.

MAYR, Otto. Adam Smith and the concept of the feedback system. Technology and culture, 12, 1971, p. 1-22.

MCCOOL, Daniel. The subsystem family of concepts: a critique and a proposal. Political research quarterly, 51, 1998, p. 551-570.

MILWARD, Brinton H.; WAMSLEY. Gary L. Policy subsystems, networks and the tools of public management. In: EYESTONE, Robert (ed.). Public Policy Formation. London: Jai Press Inc., 1984, 3-27.

OFFE, Claus. Strukturprobleme des kapitalistischen Staates. Frankfurt: Suhrkamp, 1972.

PAPADOPOLOUS, Ioannis. Governance und Demokratie. In: BENZ, Arthur (ed.). Governance - Regieren in komplexen Regelsystemen - Eine Einführung. Opladen: Leske + Budrich, 2004.

PAPPI, Franz U.; HENNING, Christian H. C. A. The organization of influence on the ecs common agricultural policy - a network approach. European journal of political research, 36, 1999, p. 257-281.

PARSONS, Talcott. Societies. evolutionary and comparative perstectives. New York: Prentice-Hall, 1966.

PERROW, Charles. Eine Gesellschaft von Organisationen. In: KENIS, Patrick; SCHNEIDER, Volker (eds.). Organisation und Netzwerk. Institutionelle Steuerung in Wirtschaft und Politik. Frankfurt: Campus, 1996, 75-121.

POULANTZAS, Nicos. L'Etat, le pouvoir, le socialisme. Paris: Press Universitaires de France, 1978.

RAAB, Jörg. Steuerung von Privatisierung. Eine Analyse der Steuerungsstrukturen der Privatisierung der ostdeutschen Werft- und Stahlindustrie 1990-1994. Wiesbaden: Westdeutscher Verlag, 2002.

SCHARPF, Fritz W. Die Handlungsfähigkeit des Staates am Erde des 20. Jahrhunderts. In: KOHLER-KOCH, Beate (ed.). Staat und Demokratie in Europa, 1992, p. 93-115.

. Interaktionsformen: Akteurszentrierter Institutionalismus in der Politikforschung. Opladen: Leske + Budrich, 2000.

SCHMITTER, Philippe C. Neocorporatism and the State. Revista espanola de investigaciones sociologicas, 31, 1985, p. 47-77. 
; LEHMBRUCH, Gerhard (eds.). Trends toward corporatist intermediation. London: Sage Publications, 1979.

SCHNEIDER, Volker. Politiknetzwerke der Chemikalienkontrolle. Eine Analyse einer transnationalen Politikentwicklung. New York: de Gruyter, 1988.

. Technikentwicklung zwischen Politik und Markt: der Fall Bildschirmtext. Frankfurt: Campus-Verl, 1989.

. Networks and games in large technical systems: The case of videotex. In: Scharpf, Fritz Wilhelm (ed.) Games in hierarchies and networks: analytical and empirical approaches to the study of governance institutions. Frankfurt: Campus, 1993, p. 251-286.

. Möglichkeiten und Grenzen der Demokratisierung von Netzwerken in der Politik. In: SYDOW, Jörg; WINDELER, Arnold (eds.). Steuerung von Netzwerken: Konzepte und Praktiken. Wiesbaden: Westdeutscher Verlag, 1999.

. Organisationsstaat und Verhandlungsdemokratie. In: WERLE, Raymund; SCHIMANK, Uwe (eds.). Gesellschaftliche Komplexität und kollektive Handlungsfähigkeit. Frankfurt: Campus, 2000, p. 243-269.

. Organizational Governance - Governance in Organisationen. In: BENZ, Arthur (ed.). Governance - Regieren in komplexen Regelsystemen. Eine Einführung. Opladen: Leske + Budrich, 2004a.

. State Theory, Governance and the Logic of Regulation and Administrative Control. In: WARNTJEN, Andreas; WONKA ARNDT, Wonka (eds.). Governance in Europe. Baden-Baden: Nomos, 2004b, p. 25-41.

. The Transformation of the State in the Digital. In: RIEKMANN, Sonja Puntscher; MOKRE, Monika; LATZER, Michael (eds.). The State of Europe. Transformations of Statehood from a European Perspective. Frankfurt: Campus, 2004c.

; WERLE, Raymund. Policy Networks in the German Telecommunications Domain. In: MARIN, Bernd; MAYNTZ, Renate (eds.). Policy Networks. Empirical Evidence and Theoretical Considerations. Frankfurt: Campus, 97-136.

SCIARINI, Pascal. Elaboration of the Swiss Agricultural Policy for the Gatt Negotiations: a Network Analysis. Schweizerische Zeitschrift für Soziologie, 22, 1996, p. 85115.

STREECK, Wolfgang; KENWORTHY, Lane. Theories and Practices of NeoCorporatism. In: JANOSKI, Thomas; ALFORD, Robert; HICKS, Alexander; SCHWARTZ, Mildred A. (eds.). Handbook of Political Sociology. New York: Cambridge University Press.

SYDOW, Jörg. Strategische Netzwerke: Evolution und Organisation. Wiesbaden: Gabler, 1995.

TAINTER, Joseph A. The collapse of complex societies. Cambridge: Cambridge University Press, 1988. 
TRUMAN, David. The governmental process. Political interests and public opinion. New York: Knopf, 1971.

UEXKÜLL, Gösta von. Lassalle. Reinbek: Rowohlt, 1974.

VANBERG, Victor. Rational choice vs. program-based behaviour. Rationality and society, 14, 2002, p. 7-54.

WATTS, Duncan. Six degrees: the science of a connected age. New York: Norton, 2003.

WILLIAMSON, Oliver E. Visible and invisible governance. The American Economic Review, 84, 1994, p. 323-326.

. Vergleichende ökonomische Organisationstheorie: Die Analyse diskreter Strukturalternativen. In: Kenis, Patrick and Schneider, Volker (eds.), Organisation und Netzwerk. Institutionelle Steuerung in Wirtschaft und Politik. Frankfurt: Campus, 1996, p. 167-212.

WILLKE, Helmut. Ironie des Staates. Grundlinien einer Staatstheorie polyzentristischer Gesellschaft: Suhrkamp, 1992.

Texto recebido em novembro de 2004 e aprovado em dezembro de 2004 . 